\title{
Health Related Quality of Life in Individuals Transferred from a Needle Exchange Program and Starting Opioid Agonist Treatment
}

\author{
Martin Bråbäck $\left(\mathbb{D},{ }^{1,2}\right.$ Louise Brådvik $\left(\mathbb{D},{ }^{2}\right.$ Katja Troberg, ${ }^{1,2}$ Pernilla Isendahl, ${ }^{2,3}$ \\ Suzan Nilsson, ${ }^{1,2}$ and Anders Håkansson (iD) ${ }^{1,2}$ \\ ${ }^{1}$ Addiction Center Malmö, Division of Psychiatry, Sweden \\ ${ }^{2}$ Lund University, Faculty of Medicine, Department of Clinical Sciences Lund, Psychiatry, Lund, Sweden \\ ${ }^{3}$ Department of Infectious Diseases, University Hospital Skåne, Malmö, Sweden \\ Correspondence should be addressed to Martin Bråbäck; martin.braback@med.lu.se
}

Received 2 October 2018; Accepted 6 December 2018; Published 19 December 2018

Academic Editor: Markus Backmund

Copyright (c) 2018 Martin Bråbäck et al. This is an open access article distributed under the Creative Commons Attribution License, which permits unrestricted use, distribution, and reproduction in any medium, provided the original work is properly cited.

\begin{abstract}
Background. Opioid agonist treatment (OAT), for the treatment of heroin dependence, has been reported to improve overall health and lower mortality. Drug use and retention in treatment have often been used as measures of treatment success. More recently, however, researchers have suggested that measurements of quality of life should be an outcome in substance use treatment evaluations. In a recent randomized controlled trial we demonstrated high rates of successful rapid referral from a needle exchange program (NEP) to OAT. The aim of this study was to see whether an improvement in health related quality of life (HRQoL) could be seen at 3-month follow-up after starting OAT and whether it was associated with any baseline characteristics. We also wanted to compare our sample to a sample from the general population with regard to HRQoL. Methods. This was a 3-month follow-up of 71 patients who started OAT. Measurements of HRQoL with EQ-5D (an instrument developed by the EuroQol group) were made at baseline and at three months. Results. Mean EQ-5D VAS (visual analogue scale) for the study sample at baseline was 47.3, which was lower than a Swedish reference population reporting 83.3. Individuals reporting being prescribed a drug for a psychiatric condition had significantly lower EQ-5D index values. Improvement in EQ-5D index score was significantly less for individuals reporting previous overdoses $(-0.10, \mathrm{p}=0.025)$. Individuals reporting previous suicide attempts had significantly lower EQ-5D VAS score at baseline. A significant increase of the EQ-5D VAS difference over time was found with a mean difference of 10.94 ( $p=0.008)$ for the total sample. Conclusion. To our knowledge this is the first time HRQoL as an outcome is reported in a population transferred from a NEP to OAT. Our results indicate that OAT can result in increased HRQoL, even with this type of rapid low-threshold referral.
\end{abstract}

\section{Introduction}

Heroin dependence is a chronic relapsing disorder with high mortality [1-3]. Opioid agonist treatment (OAT) with methadone or buprenorphine has been shown to increase social stability, improve somatic and psychiatric health, and lower overall mortality [4-6].

Traditionally when measuring treatment success we often look at the effect on drug use and retention in treatment. More recently, authors have called for a more holistic, consumeroriented perspective on treatment success, since staff and patients have been found not always to have the same view on what could be called a successful treatment [7-9].
Therefore, as a complement to "hard" outcomes like retention in treatment and drug use, several researchers suggest that measurement of quality of life (QoL) as an outcome that should be part of any substance use treatment evaluation [1013]. The field of substance abuse lags behind when it comes to these kinds of measurements; reporting of QoL is still rare and is also complicated by the fact that, when performed, several different instruments and methods are used, making comparisons difficult [13-15]. There are also differences between the two constructs QoL and health related quality of life (HRQoL). The latter addresses the individuals's selfreported health and ability to function in different domains 
concerning everyday life. HRQoL is focused on limitations caused by disease on physical, psychological, and social functioning [16], but it is sometimes misused as a synonym for QoL [17-19], which is often considered a broader concept including life domains beyond health, for example, living environment and satisfaction with life in general [13, 20]. Some authors advocate the use of QoL measurements in opioid-dependent people for a more holistic approach to treatment $[13,14,21]$. Others argue in favour of the use of HRQoL measures to be able to make calculations of quality-adjusted life years (QUALYs), which incorporates quantity of life in addition to HRQoL in a single value, as an outcome important for policy makers and when making costeffectiveness analyses when it comes to treatment of opioid dependence. At the same time they report that the use of validated HRQoL instruments is still rare in published studies regarding opioid use disorder [15].

Studies have reported that opioid-dependent individuals seeking treatment report low HRQoL as compared to the general population [22-25]. They usually report poor scores for mental health but higher ones for physical functioning [14]. Still, the initiation and retention in OAT have been shown to improve HRQoL [23, 26-33]. Factors associated with lower HRQoL among opioid-dependent individuals have been higher age [34-36], female sex [22, 37, 38], psychiatric and physical comorbidity [28, 35, 39-45], and continued use of illicit substances [41]. Examples of factors associated with improved HRQoL among opioid-dependent individuals have been improved housing conditions $[44,46]$, decreases in illicit drug use [44], and social support [47].

In a previous study we reported an opioid-dependent cohort, recruited from a needle exchange program (NEP) in Malmö, Sweden. The included participants were characterized by a high degree of drug use severity, social problems, and physical and psychiatric comorbidity, but a majority could still be rapidly transferred to OAT [48]. In this paper we report measurements of HRQoL at baseline and three months into treatment using an instrument developed by the EuroQol group, EQ-5D [49], which has been validated for heroindependent patients [50] and shown to be responsive to decreases in illicit drug use [51]. To our knowledge, evaluating HRQoL as an outcome measure has never been done in a population rapidly transferred from a NEP to evidence-based treatment with buprenorphine/naloxone or methadone.

Aims of this study were (1) a comparison of the present sample with a reference sample from the general population regarding HRQoL, (2) a comparison of variables at baseline with index scores, and (3) an investigation of overall improvement in EQ-5D scores, and the possible association with any baseline variable or use of illicit drugs during treatment.

\section{Materials and Methods}

2.1. Setting. This study took place in Malmö which is a city with a population of roughly 300000 and situated in the southern part of Sweden. Maintenance treatment with methadone was introduced in Sweden in the late 60s and buprenorphine in 1999. Traditionally, Sweden has had high thresholds to maintenance treatment and the access has been limited in many areas. The treatment is only allowed at special addiction treatment units [52]. The NEP in Malmö was started in the 80 s and is run by the Department for Infectious Diseases. It was not until 2006 that Sweden passed legislation that allowed needle exchange programs to be started also in other areas of Sweden. The legislation stated that besides preventing hepatitis and HIV needle exchange programs should motivate patients for treatment of drug dependence.

2.2. Participants and Procedures. The patient inclusion for the study took place between October 21, 2011, and April 1, 2013. The study was approved by the Regional Ethics Board Lund, Sweden. The institutional body supporting the study (the National Swedish Research Council for Working Life and Social Sciences) had no role in study design, data collection, data analysis, data interpretation, or writing of the report. All included patients signed informed consent. The patients were recruited to OAT at the NEP in Malmö. As we have reported in a previous study 71 out of 75 individuals successfully started maintenance treatment with buprenorphine or methadone at the OAT outpatient clinic [48]. Out of the four participants who did not start OAT one was arrested on her way to the OAT clinic and three did not show-up for start of OAT. The choice of medication for agonist treatment was made outside of the study protocol and the decision was based on individual clinical characteristics. Buprenorphine-naloxone was the first choice if the participant had not been in treatment before.

The individuals who entered treatment had a mean age of $39 \pm 8.6$; fifty-two were males and 19 females. The most common stated sources of income were social welfare (61\%) and criminal activities (55\%). Nine percent reported being employed and 31\% reported that they had their own apartment. On average they reported injecting 21 of 30 days the last month prior to entering treatment and the mean age for starting using heroin was 21. Eighty percent reported having hepatitis $\mathrm{C}, 31$ percent had previous suicide attempts, and 72 percent had experienced opiate overdoses. Polydrug use was common and roughly 73 percent reported using sedative-hypnotics the last 30 days prior to the baseline interview and 87 percent were positive for another illicit substance in the toxicology screen that was performed before initiating OAT.

Out of the 71 individuals who started OAT, 67 patients (94\%) were still in treatment after three months [53]. Intreatment patients had to leave observed toxicology screens twice a week. After three months, they were designated responders in treatment if 80 percent of the samples were negative for opioids and/or other illicit drugs.

The assessment took place at the NEP at baseline and after three months in treatment at the OAT outpatient clinic.

2.3. Measures. EQ-5D is a generic instrument measuring HRQoL developed by the EuroQol group [54]. It assesses five different domains of health and functioning (mobility, self-care, usual activities, pain/discomfort, and anxiety/depression) with three severity levels. The scores result in 243 different health profiles. The Swedish experienced-based value set was used to determine EQ-5D index values for each health state [55]. The index value attached to each health state 

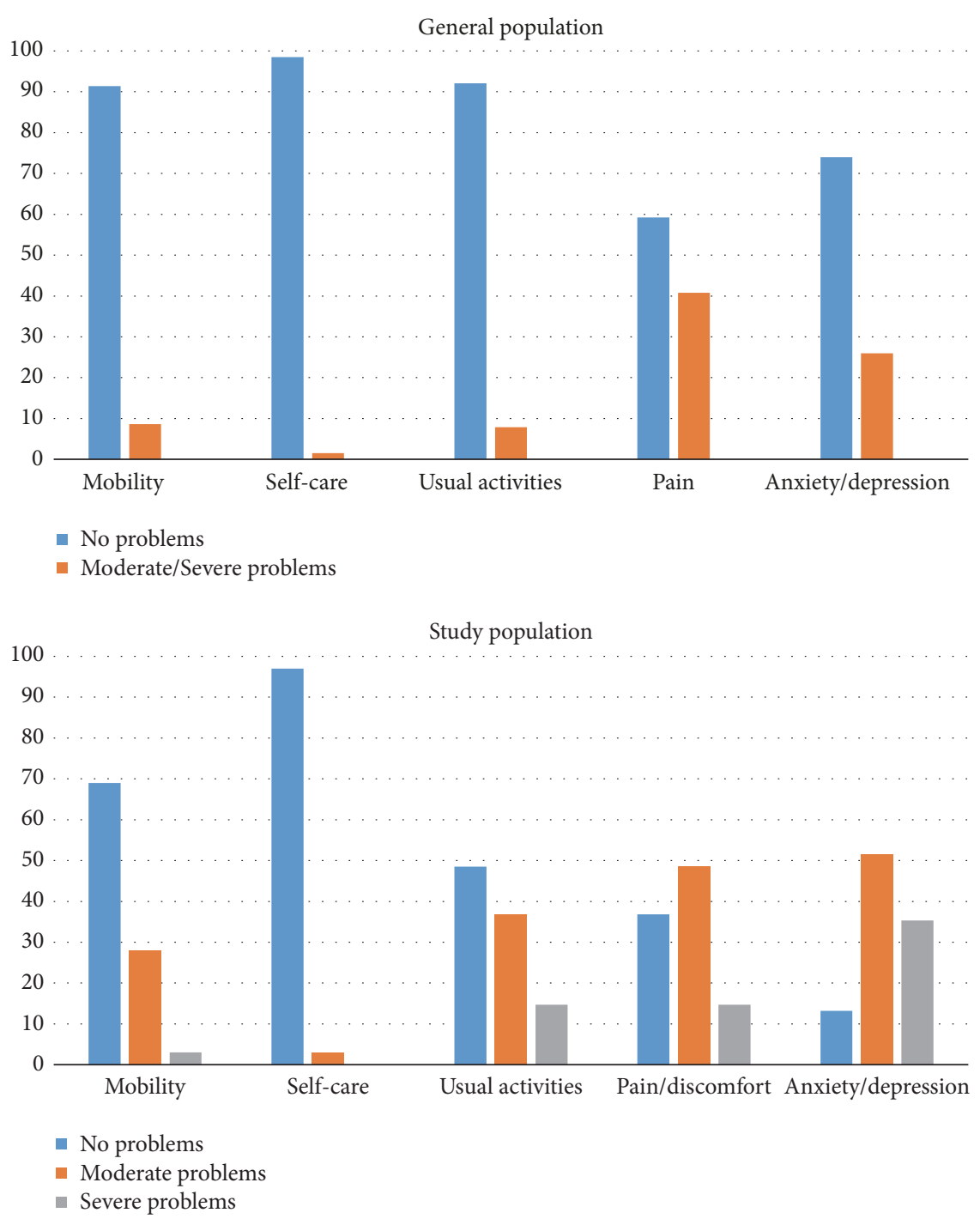

FIGURE 1: Percentage of individuals reporting problems in each EQ-5D domain in the study population compared to a general population sample from Sweden.

is on a scale between 1 (full health) and 0 (dead). The EQ$5 \mathrm{D}$ instrument includes a visual analogue scale (EQ-5D VAS) ranging from 0 to 100 where respondents rate their overall health status. The instrument can be used not only to measure the burden of disease but also to compare with samples from the general population [56].

2.4. Statistical Analysis. The difference of EQ-5D score at baseline and at three months was calculated and the variable was named "EQ-5D difference". The EQ-5D VAS difference was also calculated in the same manner. A linear regression analysis was made with the "EQ-5D difference" and the "EQ-5D VAS difference" as dependent variables. Sex, age, randomization group, being responder in treatment (defined as more than 80 percent negative toxicology screens for opioids or other illicit substances for first three months in treatment), previous suicide attempts, and previous overdoses were analyzed as independent variables. Student's t-test was used in the analysis of whether there was a statistically significant increase of the "EQ-5D difference" or "EQ-5D VAS difference" over time. The Mann-Whitney test was used for group comparisons at baseline. The statistical analysis was made with IBM SPSS Statistics (version 22).

\section{Results}

Mean EQ-5D VAS for the study sample at baseline was 47.3 which was considerably lower than a Swedish reference population who reported 83.3. More problems were also reported for all EQ-5D domains when compared to the general population sample with the highest percentage of reported problems from the domains of pain and anxiety/depression (Figure 1).

Individuals reporting being prescribed drugs for psychiatric conditions had significantly lower EQ-5D index values (Table 1). Individuals reporting previous suicide attempts had significantly lower EQ-5D VAS score at baseline. Individuals who were classified as responders (with 80 percent negative 
TABLE 1: Mean EQ-5D index scores and EQ-5D VAS scores in relation to particular reported baseline characteristics for 71 individuals starting OAT.

\begin{tabular}{|c|c|c|c|c|c|}
\hline & $\mathrm{n}(\%)$ & $\begin{array}{c}\text { EQ-5D } \\
\text { mean (s.d) }\end{array}$ & $\mathrm{p}$ & $\begin{array}{c}\text { EQ-5D VAS } \\
\text { mean (s.d) }\end{array}$ & $\mathrm{p}$ \\
\hline Male & $53(74.6)$ & $0.73(0.17)$ & 0.926 & $48.9(24.9)$ & 0.469 \\
\hline Female & $18(25.4)$ & $0.74(0.13)$ & & $42.6(28.1)$ & \\
\hline \multicolumn{6}{|c|}{ Previous suicide attempts } \\
\hline YES & $22(31.0)$ & $0.69(0.18)$ & 0.193 & $36.5(25.9)$ & 0.022 \\
\hline NO & $49(69.0)$ & $0.76(0.15)$ & & $51.8(24.5)$ & \\
\hline \multicolumn{6}{|c|}{ Prescribed psychiatric medication } \\
\hline YES & $18(25.4)$ & $0.66(0.16)$ & 0.024 & $38.1(22.5)$ & 0.078 \\
\hline $\mathrm{NO}$ & $53(74.6)$ & $0.76(0.15)$ & & $50.4(26.2)$ & \\
\hline \multicolumn{6}{|c|}{ Using benzodiazepines last 30 days } \\
\hline YES & $52(73.2)$ & $0.72(0.16)$ & 0.055 & $44.2(26.5)$ & 0.086 \\
\hline $\mathrm{NO}$ & $19(26.8)$ & $0.80(0.12)$ & & $56.2(21.5)$ & \\
\hline \multicolumn{6}{|c|}{ Responders other illicit drugs } \\
\hline YES & $9(13.2)$ & $0.89(0.10)$ & 0.004 & $63.9(21.7)$ & 0.038 \\
\hline NO & $59(86.8)$ & $0.72(0.16)$ & & $45.6(25.1)$ & \\
\hline \multicolumn{6}{|c|}{ Responders opioids } \\
\hline YES & $21(30.9)$ & $0.80(0.14)$ & 0.129 & $55.8(25.9)$ & 0.118 \\
\hline $\mathrm{NO}$ & $47(69.1)$ & $0.72(0.16)$ & & $44.6(24.7)$ & \\
\hline \multicolumn{6}{|c|}{ Previous overdoses } \\
\hline YES & $51(71.8)$ & $0.74(0.16)$ & 0.940 & $44.4(24.8)$ & 0.182 \\
\hline $\mathrm{NO}$ & $20(28.2)$ & $0.74(0.15)$ & & $54.7(27.2)$ & \\
\hline
\end{tabular}

screening for other illicit drugs) had higher mean EQ-5D index score and EQ-5D VAS score.

When performing a linear regression analysis it was found that improvement in EQ-5D index score was significantly less for the individuals with previous overdoses $(-0.10$, $\mathrm{p}=0.025)$. A significant increase of EQ-5D score difference over time was not found. A significant increase of the EQ-5D VAS difference over time was found with a mean difference of $10.94(\mathrm{p}=0.008)$ for the whole group.

\section{Discussion}

To our knowledge, this is the first time HRQoL outcomes are reported in a population recruited from a NEP and rapidly referred to OAT. Mean EQ-5D VAS at baseline was found to be considerably lower than for a sample from the general population [56]. At baseline, mean EQ-5D VAS scores were significantly lower for individuals reporting previous suicide attempts as were mean EQ-5D index scores for individuals taking a psychiatric medication, possibly indicating that more psychological problems were correlated with decreased HRQoL at baseline. Having fewer problems with polydrug use at 3-month follow-up was significantly associated with higher EQ-5D index and EQ-5D VAS scores at baseline. Improvement in EQ-5D index score was significantly less for individuals reporting previous overdoses. A significant increase of the EQ-5D VAS difference was found over time for the whole sample indicating that treatment resulted in improved HRQoL.

Sun et al. reported mean EQ-5D VAS scores for a population of homeless individuals from the central part of
Sweden [57]. They found the mean EQ-5D VAS score to be 62.6 for women and 54.9 for men; thus, it was lower compared to the general population but higher when compared to what we report for our sample (Table 1). When looking at the different domains at baseline, our population reported the most problems regarding anxiety/depression (89.8 percent), which was in accordance with Sun et al. describing homeless individuals to report the most problems in the same domain but in contrast to the reference population reporting the most problems from the domain of pain.

Most of the individuals included in the study were using other illicit substances, apart from opioids. High rates indicating polydrug use are usually common among this population of opioid-dependent individuals, in accordance with reports from other authors [58, 59]. Individuals, who at three months had 80 percent negative toxicology screens for other substances than opioids and hence were designated responders, had significantly higher mean EQ-5D index score and EQ-5D VAS score at baseline. Possibly, this may indicate that less extensive polydrug use problems are associated with higher HRQoL, as has been reported previously [25, 35].

Since psychiatric comorbidity is common in opioid dependence $[60,61]$ and as these problems have been found to lower HRQoL $[35,39,40]$ our results were not surprising. At the same time OAT has been shown to improve psychological health already during the first month of treatment [62] and more recently it has been reported to improve HRQoL as well [26-33]. In line with those results, we report a significant increase of the EQ-5D VAS difference over time. However, we could not see any significant increase of the EQ-5D index score over time for the included individuals. For individuals 
reporting previous overdoses the difference in EQ-5D index score was, however, found to be significantly less.

There are some limitations to our study. On a more general level it is difficult to compare QoL and HRQoL between studies since the instruments measure different aspects of what we consider to represent QoL. We chose to use EQ-5D, since it has been previously validated to an opioid-dependent population. At the same time it is difficult to compare our results to studies using other HRQoL instruments. Another limitation is the Swedish reference population provided by the EuroQol group for comparison, as it was relatively small and due to the fact that the EQ-5D assessment was carried out more than twenty years ago. In addition the reference population was not matched with regard to sex and age when compared to the study population [63]. Another limitation is our limited sample size. However, we could, despite that, report some statistically significant results. Major strengths of the study were the fact that all included individuals were transferred to the same OAT outpatient clinic and assessed by the same physician and research personnel, making follow-up as consistent as possible.

\section{Conclusions}

We have previously presented a low-threshold procedure for rapidly referring opioid-dependent individuals from a NEP to evidence-based treatment with methadone and buprenorphine [48]. Despite having a high degree of problems due to use of illicit substances, signs of severe psychiatric symptomatology, and social problems, patients were retained in treatment to a high degree at 12-month follow-up [53]. In conclusion, authors have however suggested that patients and staff are not always in agreement with what characterizes efficient OAT [7], that retention and reduction in substance use and other "hard" data only describe part of the truth when it comes to treatment success, and that quality of life measures should be used as part of outcome evaluation [10-12]. The present study was a 3-month follow-up of individuals rapidly transferred from a NEP to OAT with regard to HRQoL. Our results indicate that OAT can result in an increase in HRQoL even with this way of low-threshold referral.

\section{Data Availability}

The data used to support the findings of this study are available from the corresponding author upon request.

\section{Disclosure}

The institutional body supporting the study (the National Swedish Research Council for Working Life and Social Sciences) had no role in study design, data collection, data analysis, data interpretation, or writing of the report.

\section{Conflicts of Interest}

Martin Bråbäck (MB) was invited to speak at the 7th Nordic Opioid Addiction Treatment Conference 2014, Helsinki, Finland. The conference was supported by RB Pharmaceuticals.
$\mathrm{MB}$ received travel funds but no speaker fee. $\mathrm{MB}$ was also invited speaker at the Scottish Needle Exchange Conference 2014. The conference was supported by Reckitt Benckiser, neo360, Exchange supplies.org, Methameasure Ltd., Pasante, and Solutions Action Management. MB did not receive any speaker fee but travel and accommodation were covered by the organizers. Katja Troberg received travel funds from Nordic Drugs to attend ISAM in Malaysia 2014. According to Swedish legislation her public employer paid for half of the amount. Anders Håkansson (AH) has no conflicts of interest to report related to the present study. He is involved in collaborations with two pharmaceutical companies in the preparation of clinical trials unrelated to the present paper, without receiving any personal salary from these bodies. He has been the local coinvestigator in an epidemiological survey conducted by the independent research institute Research Triangle Institute (RTI), in a study for which RTI received funding from Shire, without any personal salary paid to the coinvestigators. AH holds a position in addiction medicine as an employed researcher at Lund University. For this employment, the university receives funding from the national Swedish gaming operator (Svenska Spel) owned by the Swedish government, as part of the company's legislationbased responsibility for prevention and research against gambling problems. The other authors report no relevant financial conflicts.

\section{References}

[1] A. Goldstein and J. Herrera, "Heroin addicts and methadone treatment in Albuquerque: a 22-year follow-up," Drug and Alcohol Dependence, vol. 40, no. 2, pp. 139-150, 1995.

[2] Y.-I. Hser, V. Hoffman, C. E. Grella, and M. D. Anglin, "A 33-year follow-up of narcotics addicts," Archives of General Psychiatry, vol. 58, no. 5, pp. 503-508, 2001.

[3] A. T. McLellan, D. C. Lewis, C. P. O’Brien, and H. D. Kleber, "Drug dependence, a chronic medical illness implications for treatment, insurance, and outcomes evaluation," Journal of the American Medical Association, vol. 284, no. 13, pp. 1689-1695, 2000.

[4] R. P. Mattick, C. Breen, J. Kimber, and M. Davoli, "Buprenorphine maintenance versus placebo or methadone maintenance for opioid dependence," Cochrane Database of Systematic Reviews, vol. 2, Article ID CD002207, 2014.

[5] L. Grönbladh, L. S. Öhlund, and L. M. Gunne, "Mortality in heroin addiction: impact of methadone treatment," Acta Psychiatrica Scandinavica, vol. 82, no. 3, pp. 223-227, 1990.

[6] M. T. Brugal, A. Domingo-Salvany, R. Puig, G. Barrio, P. de García Olalla, and L. de La Fuente, "Evaluating the impact of methadone maintenance programmes on mortality due to overdose and aids in a cohort of heroin users in Spain," Addiction, vol. 100, no. 7, pp. 981-989, 2005.

[7] J. Trujols, N. Siñol, I. Iraurgi, F. Batlle, J. Guàrdia, and J. Pérez de los Cobos, "Patient and clinician's ratings of improvement in methadone-maintained patients: Differing perspectives?" Harm Reduction Journal, vol. 8, 2011.

[8] J. De Maeyer, W. Vanderplasschen, J. Lammertyn, C. Van Nieuwenhuizen, B. Sabbe, and E. Broekaert, "Current quality of life and its determinants among opiate-dependent individuals 
five years after starting methadone treatment," Quality of Life Research, vol. 20, no. 1, pp. 139-150, 2011.

[9] J. De Maeyer, W. Vanderplasschen, L. Camfield, S. Vanheule, B. Sabbe, and E. Broekaert, "A good quality of life under the influence of methadone: A qualitative study among opiatedependent individuals," International Journal of Nursing Studies, vol. 48, no. 10, pp. 1244-1257, 2011.

[10] M. Torrens, "Quality of life as a means of assessing outcome in opioid dependence treatment," Heroin Addiction and Related Clinical Problems, vol. 12, no. 1, pp. 33-36, 2010.

[11] K. W. Smith and M. J. Larson, "Quality of life assessments by adult substance abusers receiving publicly funded treatment in Massachusetts," American Journal of Drug and Alcohol Abuse, vol. 29, no. 2, pp. 323-335, 2003.

[12] S. T. Tiffany, L. Friedman, S. F. Greenfield, D. S. Hasin, and R. Jackson, "Beyond drug use: A systematic consideration of other outcomes in evaluations of treatments for substance use disorders," Addiction, vol. 107, no. 4, pp. 709-718, 2012.

[13] A. B. Laudet, "The case for considering quality of life in addiction research and clinical practice.," Addiction science \& clinical practice, vol. 6, no. 1, pp. 44-55, 2011.

[14] J. De Maeyer, W. Vanderplasschen, and E. Broekaert, "Quality of life among opiate-dependent individuals: A review of the literature," International Journal of Drug Policy, vol. 21, no. 5, pp. 364-380, 2010.

[15] J. W. Bray, B. Aden, A. A. Eggman et al., "Quality of life as an outcome of opioid use disorder treatment: A systematic review," Journal of Substance Abuse Treatment, vol. 76, pp. 88-93, 2017.

[16] M. Bullinger, "Assessing health related quality of life in medicine. An overview over concepts, methods and applications in international research," Restorative Neurology and Neuroscience, vol. 20, no. 3-4, pp. 93-101, 2002.

[17] H. Rudolf and J. Watts, "Quality of life in substance abuse and dependency," International Review of Psychiatry, vol. 14, no. 3, pp. 190-197, 2002.

[18] M. Karimi and J. Brazier, "Health, Health-Related Quality of Life, and Quality of Life: What is the Difference?" PharmacoEconomics, vol. 34, no. 7, pp. 645-649, 2016.

[19] P. Moons, "Why call it health-related quality of life when you mean perceived health status?" European Journal of Cardiovascular Nursing, vol. 3, no. 4, pp. 275-277, 2004.

[20] World Health Organization, "Development of the World Health Organization WHOQOL-BREF quality of life assessment," Psychological Medicine, vol. 28, no. 3, pp. 551-558, 1998.

[21] L. Strada, W. Vanderplasschen, A. Buchholz et al., "Measuring quality of life in opioid-dependent people: a systematic review of assessment instruments," Quality of Life Research, vol. 26, no. 12, pp. 3187-3200, 2017.

[22] C. F. Ryan and J. M. White, "Health status at entry to methadone maintenance treatment using the SF-36 health survey questionnaire," Addiction, vol. 91, no. 1, pp. 39-45, 1996.

[23] M. Torrens, L. San, A. Martinez, C. Castillo, A. DomingoSalvany, and J. Alonso, "Use of the Nottingham Health Profile for measuring health status of patients in methadone maintenance treatment," Addiction, vol. 92, no. 6, pp. 707-716, 1997.

[24] P. E. Millson, L. Challacombe, P. J. Villeneuve et al., "Selfperceived health among canadian opiate users: A comparison to the general population and to other chronic disease populations," Canadian Journal of Public Health, vol. 95, no. 2, pp. 99-103, 2004.
[25] E. Puigdollers, A. Domingo-Salvany, M. T. Brugal et al., "Characteristics of heroin addicts entering methadone maintenance treatment: Quality of life and gender," Substance Use \& Misuse, vol. 39, no. 9, pp. 1353-1368, 2004.

[26] S. M. Giacomuzzi, Y. Riemer, M. Ertl et al., "Buprenorphine versus methadone maintenance treatment in an ambulant setting: A health-related quality of life assessment," Addiction, vol. 98, no. 5, pp. 693-702, 2003.

[27] O. Ubuguyu, O. C. Tran, R. D. Bruce et al., "Improvements in health-related quality of life among methadone maintenance clients in Dar es Salaam, Tanzania," International Journal of Drug Policy, vol. 30, pp. 74-81, 2016.

[28] B. Nosyk, J. W. Bray, E. Wittenberg et al., "Short term healthrelated quality of life improvement during opioid agonist treatment," Drug and Alcohol Dependence, vol. 157, pp. 121-128, 2015.

[29] P. T. Korthuis, M. J. Tozzi, V. Nandi et al., "Improved Quality of Life for Opioid-Dependent Patients Receiving Buprenorphine Treatment in HIV Clinics," Journal of Acquired Immune Deficiency Syndromes, vol. 56, pp. S39-S45, 2011.

[30] A. M. Ponizovsky and A. Grinshpoon, "Quality of life among heroin users on buprenorphine versus methadone maintenance," American Journal of Drug and Alcohol Abuse, vol. 33, no. 5, pp. 631-642, 2007.

[31] A. M. Ponizovsky, A. Margolis, L. Heled, P. Rosca, I. Radomislensky, and A. Grinshpoon, "Improved quality of life, clinical, and psychosocial outcomes among heroin-dependent patients on ambulatory buprenorphine maintenance," Substance Use \& Misuse, vol. 45, no. 1-2, pp. 288-313, 2010.

[32] A. Karow, J. Reimer, I. Schäfer, M. Krausz, C. Haasen, and U. Verthein, "Quality of life under maintenance treatment with heroin versus methadone in patients with opioid dependence," Drug and Alcohol Dependence, vol. 112, no. 3, pp. 209-215, 2010.

[33] D. W. Raisch, H. M. Campbell, D. A. Garnand et al., "Healthrelated quality of life changes associated with buprenorphine treatment for opioid dependence," Quality of Life Research, vol. 21, no. 7, pp. 1177-1183, 2012.

[34] M. R. Lofwall, R. K. Brooner, G. E. Bigelow, K. Kindbom, and E. C. Strain, "Characteristics of older opioid maintenance patients," Journal of Substance Abuse Treatment, vol. 28, no. 3, pp. 265-272, 2005.

[35] P. Millson, L. Challacombe, P. J. Villeneuve et al., "Determinants of health-related quality of life of opiate users at entry to lowthreshold methadone programs," European Addiction Research, vol. 12, no. 2, pp. 74-82, 2006.

[36] D. E. Deering, C. M. A. Frampton, J. Horn, J. D. Sellman, S. J. Adamson, and T. L. Potiki, "Health status of clients receiving methadone maintenance treatment using the SF-36 health survey questionnaire," Drug and Alcohol Review, vol. 23, no. 3, pp. 273-280, 2004.

[37] N. A. Haug, J. L. Sorensen, N. D. Lollo, V. A. Gruber, K. L. Delucchi, and S. M. Hall, "Gender differences among HIVpositive methadone maintenance patients enrolled in a medication adherence trial," AIDS Care Psychological and Sociomedical Aspects of AIDS/HIV, vol. 17, no. 8, pp. 1022-1029, 2005.

[38] A. Karow, U. Verthein, R. Pukrop et al., "Quality of life profiles and changes in the course of maintenance treatment among 1,015 patients with severe opioid dependence," Substance Use \& Misuse, vol. 46, no. 6, pp. 705-715, 2011.

[39] S. L. Batki, K. M. Canfield, E. Smyth, and R. Ploutz-Snyder, "Health-related quality of life in methadone maintenance 
patients with untreated hepatitis C virus infection," Drug and Alcohol Dependence, vol. 101, no. 3, pp. 176-182, 2009.

[40] P. J. Carpentier, P. F. M. Krabbe, M. T. van Gogh, L. J. M. Knapen, J. K. Buitelaar, and C. A. J. de Jong, "Psychiatric comorbidity reduces quality of life in chronic methadone maintained patients," American Journal on Addictions, vol. 18, no. 6, pp. 470-480, 2009.

[41] M. Astals, A. Domingo-Salvany, C. C. Buenaventura et al., "Impact of substance dependence and dual diagnosis on the quality of life of heroin users seeking treatment," Substance Use \& Misuse, vol. 43, no. 5, pp. 612-632, 2008.

[42] M. Chahua, A. Sánchez-Niubò, M. Torrens et al., "Quality of life in a community sample of young cocaine and/or heroin users: the role of mental disorders," Quality of Life Research, vol. 24, no. 9, pp. 2129-2137, 2015.

[43] S. Fassino, G. Abbate Daga, N. Delsedime, L. Rogna, and S. Boggio, "Quality of life and personality disorders in heroin abusers," Drug and Alcohol Dependence, vol. 76, no. 1, pp. 7380, 2004

[44] B. Nosyk, D. P. Guh, H. Sun et al., "Health related quality of life trajectories of patients in opioid substitution treatment," Drug and Alcohol Dependence, vol. 118, no. 2-3, pp. 259-264, 2011.

[45] A. Karow, U. Verthein, M. Krausz, and I. Schäfer, "Association of personality disorders, family conflicts and treatment with quality of life in opiate addiction," European Addiction Research, vol. 14, no. 1, pp. 38-46, 2008.

[46] S. G. Kertesz, M. J. Larson, N. J. Horton, M. Winter, R. Saitz, and J. H. Samet, "Homeless chronicity and health-related quality of life trajectories among adults with addictions," Medical Care, vol. 43, no. 6, pp. 574-585, 2005.

[47] M. Préau, C. Protopopescu, B. Spire et al., "Health related quality of life among both current and former injection drug users who are HIV-infected," Drug and Alcohol Dependence, vol. 86, no. 2-3, pp. 175-182, 2007.

[48] M. Bråbäck, S. Nilsson, P. Isendahl, K. Troberg, L. Brådvik, and A. Håkansson, "Malmö Treatment Referral and Intervention Study (MATRIS) - effective referral from syringe exchange to treatment for heroin dependence: a pilot randomized controlled trial," Addiction, vol. 111, no. 5, pp. 866-873, 2016.

[49] A. Williams, "EuroQol-a new facility for the measurement of health-related quality of life," Health Policy, vol. 16, no. 3, pp. 199-208, 1990.

[50] B. P. Van Der Zanden, M. G. W. Dijkgraaf, P. Blanken, C. A. J. M. De Borgie, J. M. Van Ree, and W. Van Den Brink, "Validity of the EQ-5D as a generic health outcome instrument in a heroindependent population," Drug and Alcohol Dependence, vol. 82, no. 2, pp. 111-118, 2006.

[51] B. Nosyk, H. Sun, D. P. Guh et al., "The quality of eight health status measures were compared for chronic opioid dependence," Journal of Clinical Epidemiology, vol. 63, no. 10, pp. 1132-1144, 2010.

[52] A. Romelsjö, B. Engdahl, M. Stenbacka et al., "Were the changes to Sweden's maintenance treatment policy 2000-06 related to changes in opiate-related mortality and morbidity?" Addiction, vol. 105, no. 9, pp. 1625-1632, 2010.

[53] M. Bråbäck, L. Ekström, K. Troberg et al., "Malmö treatment referral and intervention study-high 12-month retention rates in patients referred from syringe exchange to methadone or buprenorphine/ naloxone treatment," Frontiers in Psychiatry, vol. 8, 2017.
[54] R. Rabin and F. De Charro, "EQ-5D: a measure of health status from the EuroQol Group," Annals of Medicine, vol. 33, no. 5, pp. 337-343, 2001.

[55] K. Burström, S. Sun, U.-G. Gerdtham et al., "Swedish experience-based value sets for EQ-5D health states," Quality of Life Research, vol. 23, no. 2, pp. 431-442, 2014.

[56] C. Juan, J. Bas, and S. Agota, Self-Reported Population Health: An International Perspective based on EQ-5D, Springer, Dordrecht, Netherlands, 2014.

[57] S. Sun, K. Burström, R. Irestig, B. Burström, and U. Beijer, "Health-related quality of life (EQ-5D) among homeless persons compared to a general population sample in Stockholm County, 2006," Scandinavian Journal of Public Health, vol. 40, no. 2, pp. 115-125, 2012.

[58] J. D. Jones, S. Mogali, and S. D. Comer, "Polydrug abuse: a review of opioid and benzodiazepine combination use," Drug and Alcohol Dependence, vol. 125, no. 1-2, pp. 8-18, 2012.

[59] N. Lintzeris and S. Nielsen, "Benzodiazepines, methadone and buprenorphine: interactions and clinical management," American Journal on Addictions, vol. 19, no. 1, pp. 59-72, 2010.

[60] R. K. Brooner, V. L. King, M. Kidorf, C. W. Schmidt, and G. E. Bigelow, "Psychiatric and substance use comorbidity among treatment-seeking opioid abusers," Archives of General Psychiatry, vol. 54, no. 1, pp. 71-80, 1997.

[61] T. Rosic, L. Naji, M. Bawor et al., "The impact of comorbid psychiatric disorders on methadone maintenance treatment in opioid use disorder: A prospective cohort study," Neuropsychiatric Disease and Treatment, vol. 13, pp. 1399-1408, 2017.

[62] J. Strang, E. Finch, L. Hankinson, M. Farrell, C. Taylor, and M. Gossop, "Methadone treatment for opiate addiction: Benefits in the first month," Addiction Research \& Theory, vol. 5, no. 1, pp. 71-76, 1997.

[63] S. Björk and A. Norinder, "The weighting exercise for the Swedish version of the EuroQol," Health Economics, vol. 8, no. 2, pp. 117-126, 1999. 


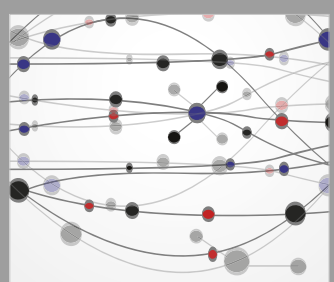

The Scientific World Journal
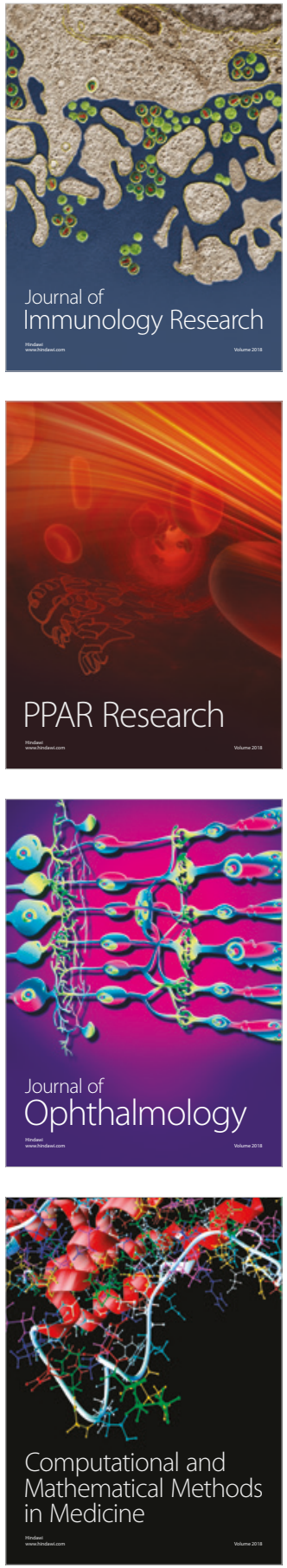

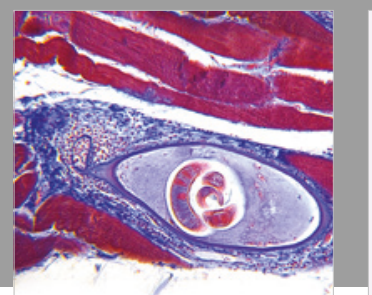

Gastroenterology Research and Practice

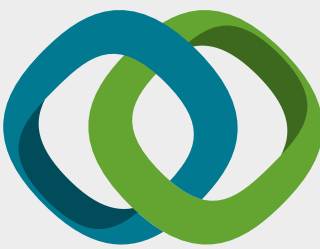

\section{Hindawi}

Submit your manuscripts at

www.hindawi.com
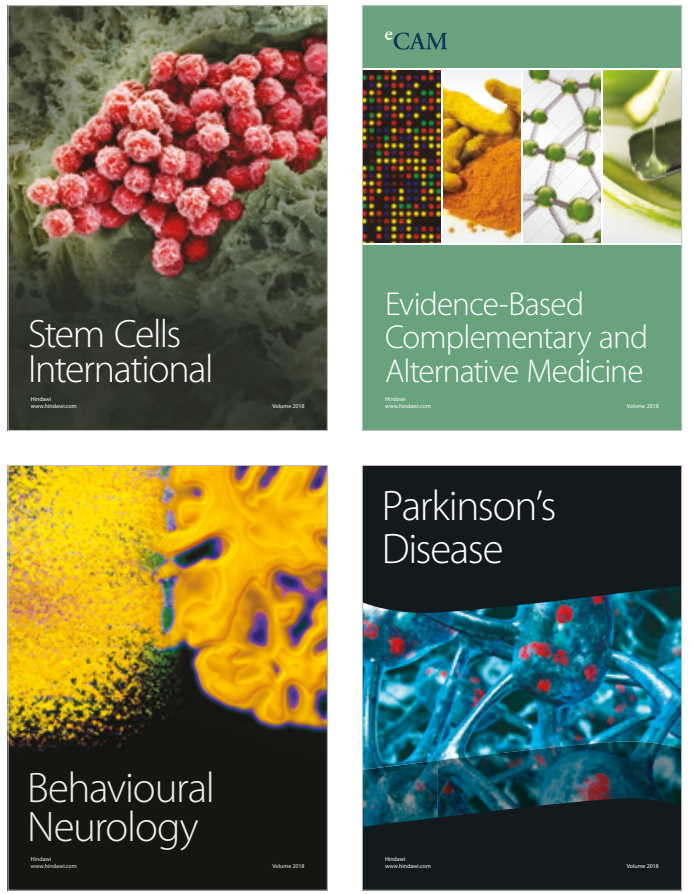

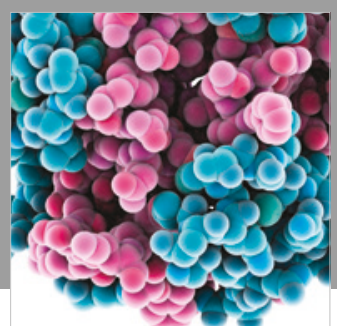

ournal of

Diabetes Research

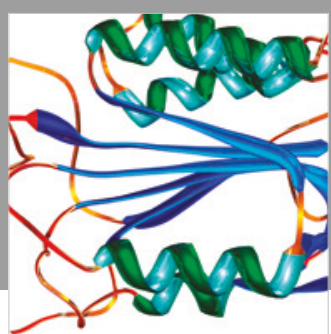

Disease Markers
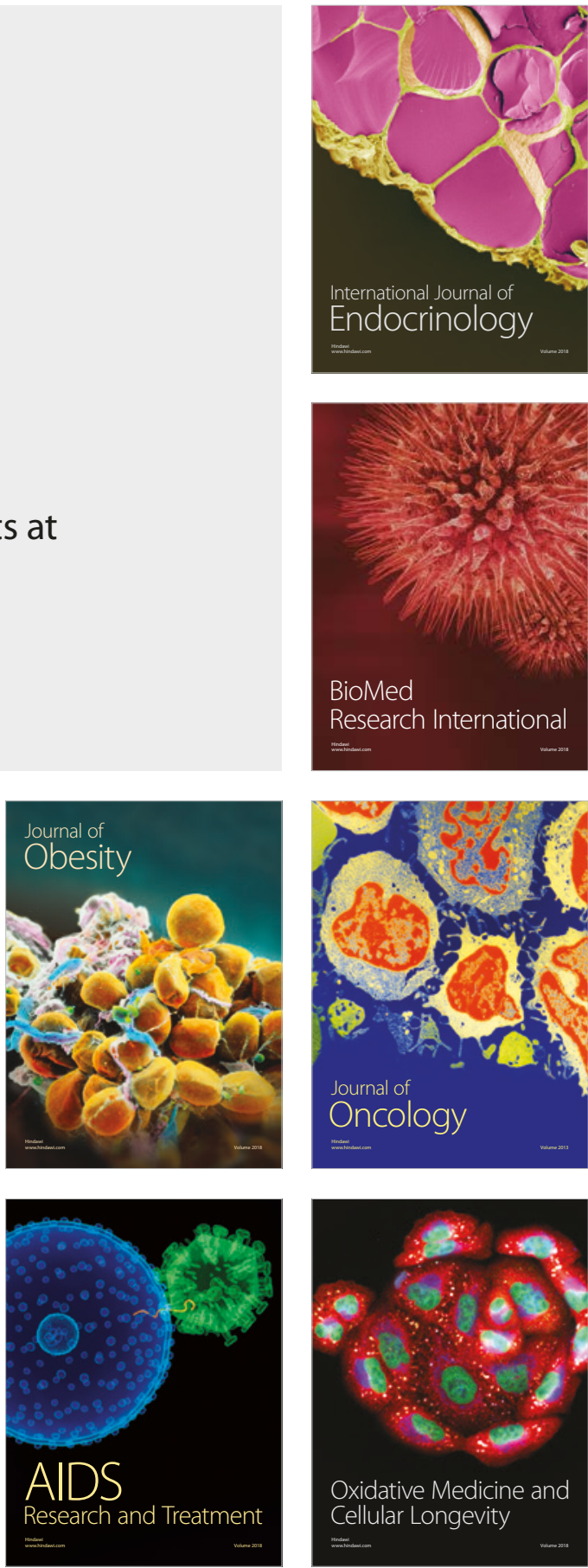